\title{
Adenovirus type 7 associated with severe and fatal acute lower respiratory infections in Argentine children Guadalupe Carballal ${ }^{* 1,3}$, Cristina Videla ${ }^{1}$, Alicia Misirlian², Paula V Requeijo ${ }^{1}$ and María del Carmen Aguilar ${ }^{2}$
}

Address: ${ }^{1}$ Laboratorio de Virología Clínica, Hospital Universitario Centro de Educación Médica e Investigaciones Clínicas "N. Quirno" (CEMIC), BuenosAires, Argentina, ${ }^{2}$ Hospital de Pediatría "Pedro de Elizalde", Buenos Aires, Argentina and ${ }^{3}$ Member of the research worker career at Consejo Nacional de Investigaciones Científicas y Técnicas (CONICET) and professor of Microbiology at the School of Medicine, Instituto Universitario CEMIC

E-mail: Guadalupe Carballal* - gcarballal@cemic.edu.ar; Cristina Videla - cvidela@cemic.edu.ar; Alicia Misirlian - aliciamisir@arnet.com.ar; Paula V Requeijo - prequeijo@ hotmail.com; María Aguilar - mcaguilar@hotmail.com

${ }^{*}$ Corresponding author

Published: 16 August 2002

BMC Pediatrics 2002, 2:6

This article is available from: http://www.biomedcentral.com/|47|-243|/2/6

(C) 2002 Carballal et al; licensee BioMed Central Ltd. This article is published in Open Access: verbatim copying and redistribution of this article are permitted in all media for any non-commercial purpose, provided this notice is preserved along with the article's original URL.
Received: 6 November 2001

Accepted: 16 August 2002

\begin{abstract}
Background: Adenoviruses are the second most prevalent cause of acute lower respiratory infection of viral origin in children under four years of age in Buenos Aires, Argentina. The purpose of this study was to analyze the clinical features and outcome of acute lower respiratory infection associated with different adenovirus genotypes in children.
\end{abstract}

Methods: Twenty-four cases of acute lower respiratory infection and adenovirus diagnosis reported in a pediatric unit during a two-year period were retrospectively reviewed. Adenovirus was detected by antigen detection and isolation in HEp-2 cells. Adenovirus DNA from 17 isolates was studied by restriction enzyme analysis with Bam HI and Sma I.

Results: Subgenus b was found in $82.3 \%$ of the cases, and subgenus c in $17.7 \%$. Within subgenus b, only genotype 7 was detected, with genomic variant $7 \mathrm{~h}$ in $85.7 \%(12 / 14)$ and genomic variant $7 \mathrm{i}$ in $14.3 \%(2 / 14)$.

Mean age was $8.8 \pm$; 6 months, and male to female ratio was 3.8: I. At admission, pneumonia was observed in $71 \%$ of the cases and bronchiolitis in $29 \%$. Malnutrition occurred in $37 \%$ of the cases; tachypnea in $79 \%$; chest indrawing in $66 \%$; wheezing in $58 \%$; apneas in $16 \%$; and conjunctivitis in $29 \%$. Blood cultures for bacteria and antigen detection of other respiratory viruses were negative.

During hospitalization, fatality rate was $16.7 \%$ (4/24). Of the patients who died, three had $\mathrm{Ad} 7 \mathrm{~h}$ and one Ad 7i. Thus, fatality rate for adenovirus type 7 reached $28.6 \%(4 / 14)$.

Conclusions: These results show the predominance of adenovirus 7 and high lethality associated with the genomic variants $7 \mathrm{~h}$ and $7 \mathrm{i}$ in children hospitalized with acute lower respiratory infection.

\section{Background}

Acute respiratory infection of the lower tract is a serious cause of morbidity and mortality in young children, particularly in developing countries, where the risk of death 
is 30 times higher than in the northern hemisphere [1]. In Argentina, acute lower respiratory infection is the third cause of death in children under one year of age [Miceli, I., Ministerio de Salud Pública y Acción Social, personal communication].

In the northern hemisphere, viruses are the agents most frequently associated with acute lower respiratory infections in children under 5 years of age. Adenoviruses (Ad) are the third viral agent (3\%) after Respiratory Syncytial virus (RSV) (32-36\%) and Parainfluenza viruses (17\%) $[2,3]$. In Sweden, Ad are responsible for $5 \%$ of acute lower respiratory infection in hospitalized children [4]. Respiratory diseases are usually caused by Ad from subgenus b (serotypes 3 and 7), subgenus c (serotypes 1,2 and 5), and subgenus e (serotype 4) [4].

In Buenos Aires, Argentina, viruses are also the first cause of acute lower respiratory infection in children under 5 years of age [5]. In this population, Ad proved to be the second viral agent after RSV, with detection rates of $2.7 \%$
(27 Ad cases/1,003 patients) [5] and 2.5\% (31 Ad cases/ 1,234 patients) [6] in inpatients under 5 years of age. However, higher Ad frequencies were observed in specialized hospitals, where rates reached $14.3 \%$ [7] and 34\% [Mistchenko, A, 1996, personal communication].

Restriction enzyme analysis of viral DNA provides an essential tool for epidemiological studies, allowing the typing of Ad to subgenus level and the differentiation of genomic variants within a given serotype [4]. In the Southern Cone countries, molecular studies of Ad isolated from children with lower respiratory infection have shown the predominance of the genome type $7 \mathrm{~h}$. This variant was repeatedly associated with severe and frequently fatal outcome of necrotizing bronchiolitis or pneumonia [8-12].

The objective of this study was to analyze the clinical features and outcome of acute lower respiratory infection associated with different adenovirus genotypes in hospitalized children.

Table I: Clinical features at admission of children with acute lower respiratory infection with and without adenovirus infection

\begin{tabular}{|c|c|c|c|c|c|}
\hline \multirow[t]{2}{*}{ Features } & \multicolumn{2}{|c|}{$\begin{array}{l}\text { With Adenovirus infection } \\
n=24\end{array}$} & \multicolumn{2}{|c|}{$\begin{array}{l}\text { Without Adenovirus infection* } \\
\qquad n=75\end{array}$} & \\
\hline & n & $\%$ & $\mathbf{n}$ & $\%$ & \\
\hline \multicolumn{6}{|l|}{ Age (months) } \\
\hline $0-11$ & 18 & $(75)$ & 63 & $(84)$ & \\
\hline $12-24$ & 6 & $(25)$ & 12 & (16) & \\
\hline Mean age \pm SE months & \multicolumn{2}{|c|}{$8.8 \pm 6$} & \multicolumn{2}{|c|}{$6.8 \pm 6.7$ ** } & ns \\
\hline \multicolumn{6}{|l|}{ Sex } \\
\hline Male/female ratio & \multicolumn{2}{|c|}{$3.8: 1$} & \multicolumn{2}{|c|}{$2.7: 1^{* \alpha * k}$} & ns \\
\hline \multicolumn{6}{|c|}{ Diagnosis at admission } \\
\hline Pneumonia & 17 & (7I) & 36 & $(48)^{* * * *}$ & ns, $p<0.05$ I \\
\hline Bronchiolitis & 7 & (29) & 39 & $(52)$ & \\
\hline \multicolumn{6}{|l|}{ Nutritional Status } \\
\hline Malnutrition & 9 & $(37.5)$ & 25 & $(33.8)$ & \\
\hline Breast feeding & 14 & $(58.3)$ & 43 & $(57.5)$ & \\
\hline \multicolumn{6}{|l|}{ Signs and Symptoms } \\
\hline Fever $\left(>38^{a} C\right)$ & 20 & $(83)$ & 49 & $(65)$ & \\
\hline Rhinorrhea & 17 & $(70.8)$ & 51 & $(67.5)$ & \\
\hline Tachypnea & 19 & $(79.2)$ & 59 & (78.8) & \\
\hline Respiratory rate/min & \multicolumn{2}{|c|}{$40.0 \pm 28.0$} & \multicolumn{2}{|c|}{$39.0 \pm 31.0$} & \\
\hline Cough & 18 & $(75)$ & 55 & $(73.8)$ & \\
\hline Chest indrawing & 16 & $(66.6)$ & 52 & $(68.8)$ & \\
\hline Wheezing & 14 & $(58.3)$ & 29 & $(38.8)$ & \\
\hline Roncus & 12 & $(50)$ & 29 & (38.8) & \\
\hline Rales & 18 & (75) & 57 & (76.3) & \\
\hline Apneas & 4 & $(16.6)$ & 7 & $(8.8)^{* * * *}$ & ns \\
\hline Conjunctivitis & 7 & (29) & 17 & $(22.5)$ & \\
\hline
\end{tabular}

* Children admitted to this hospital with ALRI, in whom RSV and Adenovirus diagnosis were excluded. ${ }^{* *}$ "t" Student test ; ${ }^{* * *} \mathrm{X}^{2}$ test; ns: not significant 


\section{Methods \\ Population}

Children included in this study were selected from a group of 168 patients with ALRI, admitted to a unit of the " P de Elizalde" Hospital in Buenos Aires, between May 1991 and December 1992 [7]. Clinical records from 24 children with Ad infection, (24/168) (14,3\%), were retrospectively reviewed. Data from 75 children with neither RSV nor Ad infection were also analyzed.

Ad diagnosis was made by both indirect immunofluorescence and culture isolation. Children eligible for the study were those under 2 years of age, with clinical diagnosis of pneumonia or bronchiolitis, and less than 7 days of evolution at admission. Children with a history of asthma, HIV diagnosis, cystic fibrosis, measles or nosocomial infections were excluded.

Clinical diagnoses of pneumonia or bronchiolitis were made by both physical examination and chest X-ray, following the WHO guidelines [13]. Nasopharyngeal aspirate and blood culture for bacteria were obtained at admission. An informed consent signed by parents was obtained in all cases.

\section{Virological Methods}

\section{Ad detection}

Nasopharyngeal aspirates were processed at CEMIC Virology Laboratory. Antigen detection was performed by indirect immunofluorescence with a monoclonal antibody
(Chemicon, USA) and isolation was made in HEp-2 cells as described in the literature $[7,13]$. Genomic analyses were performed 2 years later. Ad isolates, kept at $-70^{\circ} \mathrm{C}$, were amplified in HEp-2 cells; viral DNA was extracted and studied by restriction enzyme analysis with Bam HI and Sma I endonucleases as previously described $[10,14]$.

\section{Bacteriologic methods}

Blood cultures obtained at admission and stools from children who developed diarrheawere studied by standard methods at "P. de Elizalde" Hospital.

\section{Results}

\section{Clinical features at admission (Table I)}

Mean age was $8.8 \pm 6$ months, and $75 \%$ of the patients were between 6 and 24 months old. Male to female ratio was 3.8: 1. Clinical diagnoses were pneumonia (71\%) and bronchiolitis (29\%). Malnutrition was detected in $37.5 \%$ of the cases, and 58\% were breast fed.

The severity of the disease may be inferred from the high rates of tachypnea $(79.2 \%)$, rales $(75 \%)$, chest indrawing (66.6\%), wheezing (58.3\%), and apneas (16.6\%). In addition to respiratory signs, $29 \%$ of the patients presented conjunctivitis. Although no statistically significant differences in signs and symptoms were observed between children with Ad and those without RSV or Ad infection, pneumonia was more frequently found in children with Ad.

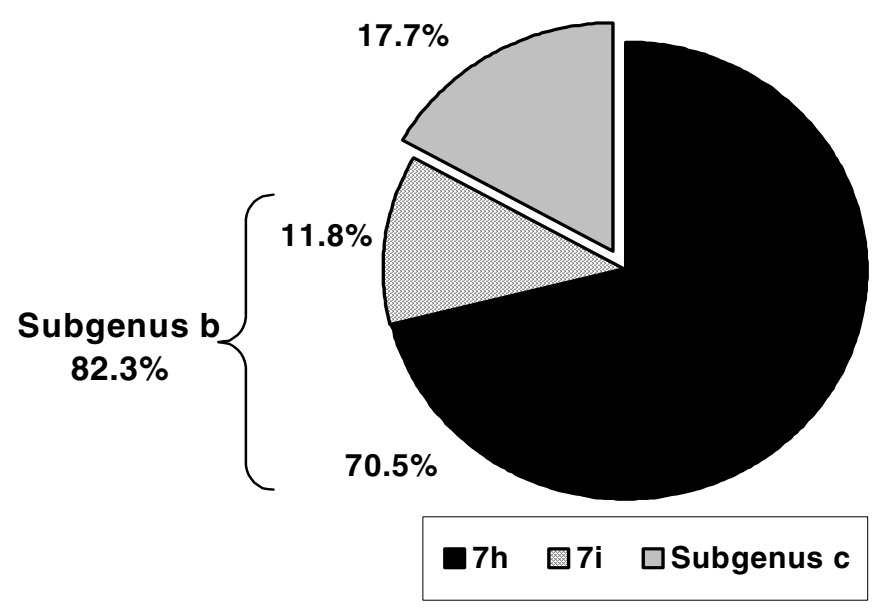

\section{Figure I}

Genome analysis of 17 adenovirus isolated from children with acute lower respiratory infection. 
Table 2: Clinical features, outcome and adenovirus genotypes in 17 children with acute lower respiratory infection

\begin{tabular}{cccccc}
\hline $\begin{array}{c}\text { Case Admission } \\
\#\end{array}$ & Sex & $\begin{array}{c}\text { Age De } \\
\text { months }\end{array}$ & Diagnosis & Genotype Outcome \\
\hline
\end{tabular}

1991

\begin{tabular}{|c|c|c|c|c|c|c|c|}
\hline 1 & Sept & $M$ & 2 & Multifocal Pneumonia & Malnutrition Grade I & 2D7 & NF \\
\hline 2 & Oct & M & 24 & Bilateral Pneumonia & None & 7h & Dead'Sepsis, pneumonia \\
\hline 3 & Nov & M & 3 & Multifocal Pneumonia & $\begin{array}{l}\text { Malnutrition Grade II, Diarrhea } \\
\text { Preterm }\end{array}$ & 7h & $\begin{array}{l}\text { Dead** Reye Syndrome, } \\
\text { pneumonia }\end{array}$ \\
\hline 4 & Nov & $M$ & 8 & Bronchiolitis & Previous lung Sequelae, Preterm & 7h & NF \\
\hline
\end{tabular}

\section{2}

\begin{tabular}{|c|c|c|c|c|c|c|c|}
\hline 5 & Feb & $M$ & 3 & Bronchiolitis & Preterm & $|D|$ & Discharged \\
\hline 6 & Feb & $M$ & 6 & $\begin{array}{l}\text { Bronchiolitis, Con- } \\
\text { junctivitis }\end{array}$ & None & $|D|$ & Discharged \\
\hline 7 & Mar & $\mathrm{F}$ & 7 & Pneumonia & Congenital heart disease & $7 \mathrm{~h}$ & NF \\
\hline 8 & July & $M$ & 12 & Pneumonia & Previous ALRI & $7 \mathrm{~h}$ & NF \\
\hline 9 & July & $M$ & 2 & Bronchiolitis & None & $7 \mathrm{~h}$ & NF \\
\hline 10 & July & $M$ & 15 & Pneumonia, Otitis & Anemia & $7 \mathrm{~h}$ & Discharged \\
\hline 11 & Aug & $M$ & 8 & Pneumonia, Otitis & None & $7 \mathrm{~h}$ & Dead, pneumonia \\
\hline 12 & Aug & $\mathrm{F}$ & 2 & Pneumonia & $\begin{array}{l}\text { Congenital heart disease Malnu- } \\
\text { trition Grade II }\end{array}$ & $7 \mathbf{i}$ & Dead $^{* * *}$, empyema \\
\hline 13 & Aug & $M$ & 9 & Pneumonia & Macrocephaly & $7 \mathbf{i}$ & NF \\
\hline 14 & Sept & $M$ & 8 & Bifocal Pneumonia & Hydrocephalus & $7 \mathrm{~h}$ & Discharged \\
\hline 15 & Oct & $M$ & 8 & $\begin{array}{l}\text { Bifocal Pneumonia, } \\
\text { Conjunctivitis }\end{array}$ & None & $7 \mathrm{~h}$ & NF \\
\hline 16 & Nov & $M$ & 2 & Pneumonia & None & $7 \mathrm{~h}$ & NF \\
\hline 17 & Nov & $M$ & 6 & $\begin{array}{l}\text { Pneumonia, Conjunc- } \\
\text { tivitis }\end{array}$ & Hypogammaglobulinemia & $7 \mathrm{~h}$ & Discharged \\
\hline
\end{tabular}

In all cases, blood cultures for bacteria were negative at admission. During diarrhea, the following bacteria were recovered from stools: ${ }^{*}$ Klebsiella; ** Pseudomona; ${ }^{* * * k}$ Salmonella. NF: not followed. Six patients were not followed because their parents took them from our hospital after the acute stage of the disease. Therefore, the outcome is not available.

\section{Frequency of Ad genotypes (Figure I)}

The 24 Ad cases found by antigen detection on nasopharyngeal aspirates were also isolated in culture. Ad strains were kept at $-70^{\circ} \mathrm{C}$ until genomic analysis was performed 2 years later. Only 17 strains were recovered in culture, since the rest failed to be appropriately amplified. Molecular restriction analysis with Bam HI and Sma I was performed in the amplified strains, and showed subgenus $b$ in $82.3 \%$ (14 strains) and subgenus $c$ in $17.7 \%$ (3 strains). Within subgenus $b$, the genome type most frequently detected was Ad 7h (85.7\%) (12 strains), while Ad $7 \mathrm{i}$ was found in $14.2 \%$ (2 strains). Within the subgenus c strains, genome types Ad 2D7 were detected in 1 case, and Ad 1D1 in another 2 cases.

\section{Clinical features and outcome of I 7 patients and Ad geno- types (Table 2)}

At admission, all blood cultures were negative for bacteria, and no other respiratory viruses were detected in nasopharyngeal aspirates.

Out of the 12 patients with Ad 7h, 3 died, 3 recovered 12 weeks after hospitalization, and 6 were lost to follow up because their parents took them to another hospital. Regarding the 3 fatal cases with Ad $7 \mathrm{~h}$, bacterial etiology could not be clearly associated with death. In case \# 11, all bacterial cultures were negative. A Klebsiella was detected in the stools of case \# 2, and a Pseudomonas in the stools of case \# 3 .

The fatal case associated with Ad $7 \mathrm{i}$ was a 2 -month-old female with congenital heart disease and malnutrition 
grade II (case \# 12). This patient died with empyema 10 days after hospitalization and mechanical ventilation, and a non-typhi Salmonella was recovered from her stools.

Regarding the patients who recovered from Ad $7 \mathrm{~h}$ infection and were discharged, 3 presented underlying conditions: case \# 10 anemia, case \#14 hydrocephalus, and case \# 17 hypogammaglobulinemia.

\section{Fatality rate (Table 3)}

The overall case fatality rate in hospitalized children with acute lower respiratory infection and associated Ad infection was $16.7 \%$ (4/24). Considering only Ad 7 cases, case lethality reached $28.6 \%$. Ad $7 \mathrm{~h}$ was found in the respiratory samples of three patients, and Ad $7 \mathrm{i}$ in one.
Of the 3 patients who died with Ad 7h, 2 presented no underlying conditions, while 1 (case \# 3 ) was a preterm male with malnutrition grade II. No fatal cases were recorded among the 75 children who presented neither RSV nor Ad infection.

Table 3: Fatality rate during hospitalization associated with adenovirus genome type 7 in children with acute respiratory infection of the lower tract

\begin{tabular}{ccc}
\hline Case Fatality Rate & $\begin{array}{c}\text { Fatalities/patients } \\
\text { with Ad }\end{array}$ & $(\%)$ \\
\hline Ad Genome type 7 & $4 / 14$ & $(28.6)$ \\
Genomic variant Ad 7h & $3 / 12$ & $(25)$ \\
Genomic variant Ad 7i & $1 / 2$ & $(50)$ \\
Total (all variants) & $4 / 24$ & $(16.7)$ \\
\hline
\end{tabular}

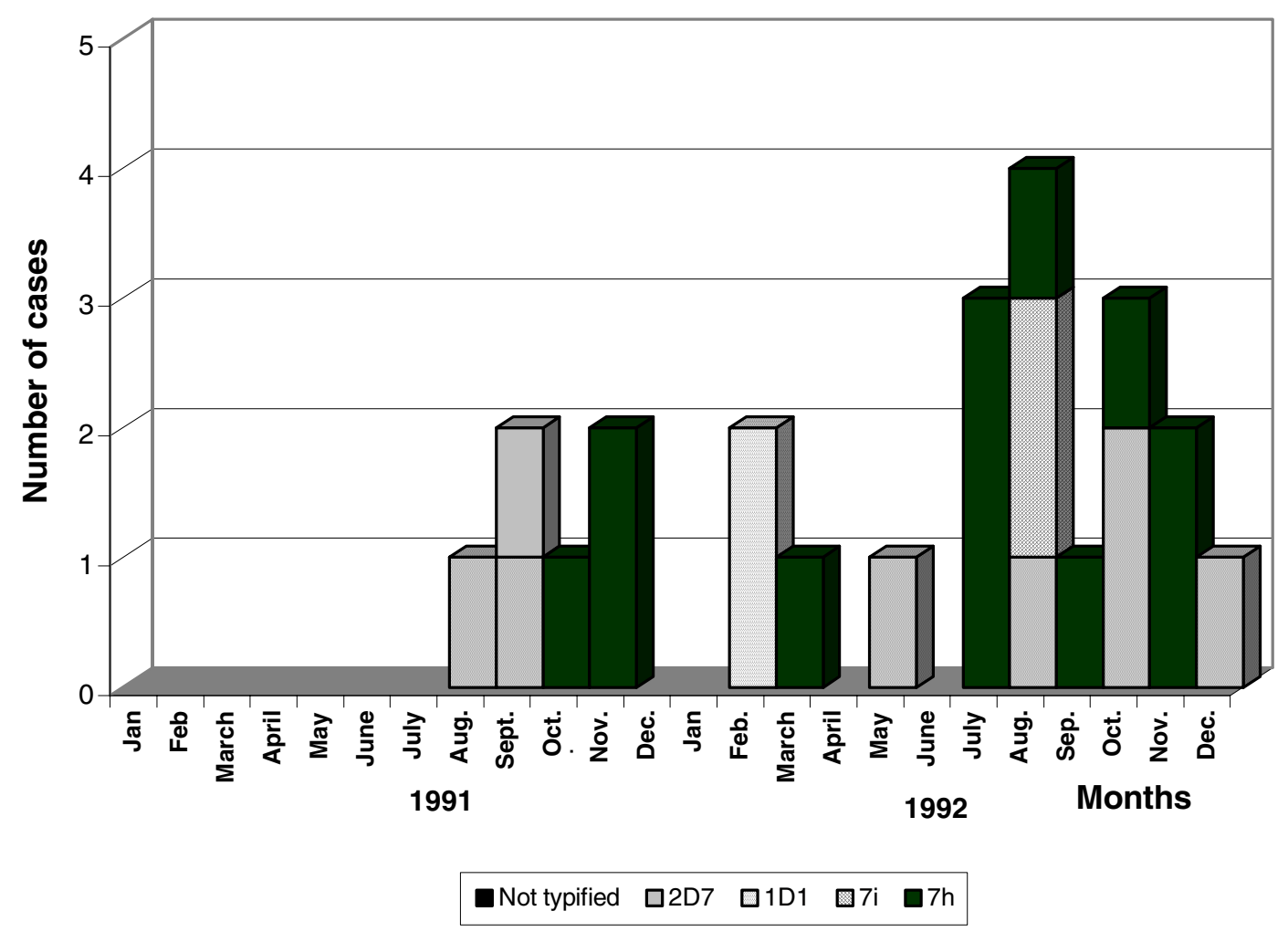

Figure 2

Monthly distribution of 24 adenovirus cases in children under 2 years of age hospitalized with acute lower respiratory infection. 


\section{Seasonal distribution of Adenovirus genotypes (Figure 2)} Ad cases were detected throughout the 2-year study period. Different patterns were observed in 1991 and 1992. In 1991, Ad cases were not found in winter but in spring. In 1992, the first Ad cases, Ad 1D1, occurred in February. The first Ad $7 \mathrm{~h}$ was recorded in March. In winter, 3 cases were detected in July and 1 in August. Another 4 Ad 7 h cases were recorded in spring. The 2 Ad $7 \mathrm{i}$ were detected in August, 1992.

\section{Discussion}

Children included in this study were selected from a group of 168 patients with acute lower respiratory infection studied in a pediatric hospital for two consecutive years. RSV was the most frequently detected virus (36.3\%) (61/168), followed by Ad (14.3\%) (24/168) (p < 0.0001) [7]. The clinical features and outcomes of 24 children with Ad diagnosis were analyzed according to different Ad genotypes.

The frequency of community acquired Ad infection detected in this hospital in the studied period (14.3\%) was higher than that reported for primary care centers in Buenos Aires city $(2.5 \%)[5,6,14]$. The diagnostic methods used in those studies were immunofluorescence and/ or culture. Probably, the use of more sensitive procedures such as PCR, currently available, would have increased these frequencies. [15-18]

Patients attending this hospital lived under low socioeconomic conditions in poor areas of the city. Ad were highly associated with pneumonia (71\%) rather than with bronchiolitis (21\%), (Table 1 ) and were more frequently observed in males and in children older than 6 months. In 1991, Ad were detected in spring and at the end of winter, and in 1992, in spring (Figure 2). In contrast, RSV was mainly associated with bronchiolitis in younger children, and the outbreak showed a clear peak during the winter of the two years studied [7].

A predominance of Ad subgenus b (82.3\%) was observed, with genome type $7 \mathrm{~h}$ being the most frequently detected (85.7\%) (Figure 1).

The long lasting predominance of a few genomic types of Ad in a certain region has been reported for other countries [19], as shown in a study of 212 Ad strains isolated in the Southern Cone countries from 1984 to 1990. Between 1984 and 1985, Ad 7c was the predominant strain, while a switch to Ad $7 \mathrm{~h}$ was observed in 1986. Thereafter, the circulation of Ad $7 \mathrm{~h}$ has been documented in children with community acquired necrotizing bronchiolitis or severe pneumonia in Buenos Aires [6,8-11,20,21]. Furthermore, certain hospitals have reported nosocomial outbreaks in crowded conditions, which are associated with high case lethality and development of lung sequelae [9].

In the present study, the overall fatality rate during hospitalization of patients with Ad 7 reached 28.6\%. Of these patients, 3 had Ad $7 \mathrm{~h}$, and 1 Ad $7 \mathrm{i}$. These severe cases could be strongly associated with Ad 7, since antigen detection of other respiratory viruses and blood cultures for bacteria were negative. Bacteria isolated from stools of the 3 children who developed diarrhea cannot be the main cause of death. Furthermore, among fatal cases with Ad $7 \mathrm{~h}$, no underlying conditions were observed in patients \# 2 and \# 11, while case \# 3 was a preterm child with malnutrition grade II.

The fatal case with Ad $7 \mathrm{i}$ was a 2-month-old female with a congenital heart disease and malnutrition (\# 12). When studied with 8 different restriction enzymes, Ad $7 \mathrm{i}$ proved to be closely related to Ad $7 \mathrm{~h}$, only differing in the restriction patterns with Bam HI and Cfo $[8,11,22,23]$.

Murtagh et al. [9] reported a case lethality of $34.5 \%$ (10 fatalities / 29 patients) in pediatric acute lower respiratory disease associated with Ad $7 \mathrm{~h}$ at Garraham Hospital in Buenos Aires. In this series, $52 \%$ of the children recovered, but $14 \%$ developed severe lung sequelae. Pathogenic mechanisms involved in Ad infection of the respiratory tract are unclear. Therefore, neither specific treatment nor vaccines for civilian population are available. The role of maternal antibodies has not yet been studied.

Different sequences in the early region E3 or in the fiber have been suggested to result in diverse degrees of virulence or tropism by encoding proteins that may modulate the immune response and play a role in pathogenesis $[24,25]$. Although host risk factors such as immunodeficiencies, malnutrition or previous viral infections have been suggested to have an effect on the development of severe Ad infection, higher pathogenicity of some genome types is clearly associated with a fatal outcome [26]. This is the case of Ad 7h in Argentina, as shown once more in this paper.

Ad $7 \mathrm{~h}$ has been recently isolated from children with upper respiratory infection in Japan. The authors reported that these strains are closely related to the Argentine Ad 7h, and suggested the spread of this emerging virus from South America to Japan, since Ad 7 was absent from this country for several decades [27].

In Argentina, lack of a national surveillance program for Ad infection, scarcity of autopsies, and difficulties in the follow up of patients for detection of lung sequelae restrict our knowledge of the general impact of Ad infection. Fur- 
ther studies should be performed to elucidate the epidemiology of Ad in pediatric respiratory infections.

\section{Conclusions}

The results herein obtained show predominance of adenovirus $7(82 \%)$ and high lethality associated with the genomic variants $7 \mathrm{~h}$ and $7 \mathrm{i}(28.6 \%)$ in children hospitalized with acute lower respiratory infection.

\section{Competing interests}

None declared.

\section{Authors' contributions}

GC designed the study and wrote the paper. CV carried out the virologic study and participated in writing the paper. AM was in charge of patients' examination. PVR performed the statistical analysis. MCA was in charge of patients' examination.

\section{Acknowledgments}

This study was supported in part by grants from CONICET (33-8I500/92); University of Buenos Aires (0I/TMO6), and Fundación René Baron. The skillful technical assistance of $C$ Juarez, $C$ Ricarte and B Ebekian is gratefully acknowledged. We thank Dr A. Kajon for genomic typification.

\section{References}

I. Organización Panamericana de la Salud (OPS): Infecciones respiratorias agudas en las Américas. Boletín Epidemiológico OPS 1995, 16:1-5

2. Glezen WP, Lodon FA, Clyde WA: Epidemiologic pattern of acute lower respiratory disease of children in pediatric group practice. Journal of Pediatrics 197I, 78:397-406

3. Taussing LM, Wright AL, Morgan WJ, Harrison RH, Ray CG, The group Health Medical Associates: The Tucson children's respiratory study. I Design and implementation of a prospective study of acute and chronic respiratory illness in children. American Journal of. Epidemiology 1989, | 29:|219-123|

4. Sharp IR, Wadell G: Adenoviruses. Principles and Practice of Clinical Virology 3 Edition (Edited by: A. Zukerman, J. Banatvalla and J.R. Pattison) John Wiley and sons Ltd 1995, Third edition:287-308

5. Weissembacher M, Carballal G, Avila M, Salomón H, Harisiadi J, Catalano M, Cerqueiro MC, Murtagh P: Etiologic and clinical evaluation of acute lower respiratory tract infections in young Argentinian children: an overview. Review of Infectious Disease 1990, I 2(8):S889-898

6. Carballal G, Videla C, Espinosa M, Savy V, Uez O, Sequeira M, Knez V, Requeijo P, Riva Posse C, Miceli I: Multicentered study of viral acute lower respiratory infections in children from four cities of Argentina, 1993-1994. Journal of Medical Virology 200I, 64:167-174

7. Videla C, Carballal G, Misirlian A, Aguilar M: Acute lower respiratory infections due to Respiratory Syncytial Virus and Adenovirus among hospitalized children from Argentina. Clinical and Diagnostic Virology 1998, 10:17-23

8. Kajon A, Wadell G: Molecular epidemiology of Adenovirus associated with lower respiratory disease of children in Buenos Aires, Argentina (1984-1988). Journal of Medical Virology 1992, 36:292-297

9. Murtagh P, Cerqueiro C, Halac A, Avila M, Kajon A: Adenovirus type $7 \mathrm{~h}$ respiratory infections: a report of 29 cases of acute lower respiratory disease. Acta Pediatr 1993, 82:557-56|

10. Kajon A, Wadell G: Genome Analysis of South American Adenovirus Strains of Serotype 7 collected over a 7 year period. Clin Microbiol 1994, 32(9):232I-2323

II. Kajon A, Mistchenko A, Videla C, Hortal M, Wadell G, Avendaño L: Molecular Epidemiology of Adenovirus Acute Lower Respiratory Infections of Children in the South Cone of South America (1989-1994). Journal of Medical Virology 1996, 48: I5I-I56
12. Larranaga C, Kajon A, Villagra E, Avendaño LF: Adenovirus surveillance on children hospitalized for acute lower respiratory infections in Chile (1988-1996). Journal of. Medical Virology 2000, 60(3):342-346

13. Board of Science and Technology for International Development (BOSTID) Research Grants: Program on Etiology and Epidemiology of Acute Respiratory Infections in Children Manual of laboratory procedures for diagnosis of respiratory virus infections. Washington DC 1986

14. Shinagawa $M$, Marsuda $A$, Ishiyana $T$, Goto $H$, Soto G: A rapid and single method for preparation of Adenovirus DNA from infected cells. Microbiology and Immunology 1983, 27(9):8I7-822

15. Allard A, Albinsson B, Wadell G: Rapid typing of human adenoviruses by a general PCR combined with restriction endonuclease analysis. J Clin Microbiol 200 I, 39:498-505

16. Avellon A, Perez P, Aguilar JC, Lejarazu R, Echevarria JE: Rapid and sensitive diagnosis of human adenovirus infections by a generic polymerase chain reaction. J Virol Methods 200I, 92:113120

17. Echavarria M, Kolavic SA, Cersovsky S, Mitchell F, Sanchez JL, Polyak C, Innis BL, Binn LN: Detection of adenoviruses (AdV) in culture-negative environmental samples by PCR during an AdV-associated respiratory disease outbreak. I Clin Microbiol 2000, 38:2982-2984

18. Pring-Akerblom P, Adrian T, Kostler T: PCR-based detection and typing of human adenoviruses in clinical samples. Res Virol 1997, 148:225-231

19. Li QG, Wadell G: Analysis of 15 different genome types of Adenovirus type 7 isolated on five continents. Journal of Virology 1986, 60:33|-335

20. Carballal G, Siminovich M, Murtagh P, Cerqueiro C, Avila M, Salomón $\mathrm{H}$, Catalano M, Weissembacher M: Etiologic, clinical and pathologic analysis of $32 \mathrm{fatal}$ cases of acute respiratory infections in Argentinian children under $\mathbf{5}$ years old. Rev Infect Dis 1990, I 2(Supp| 8):SI074-SI080

21. Niel C, Moraes MTB, Mitschenko AS, Leite JPG, Gomes S: Restriction site mapping of four genome types of adenovirus types 3 and 7 isolated in South America. Journal of Medical Virology 1991, 33:123-127

22. Baumeister EG, Fernandez Cobo M, Savy V: Detección de una variación genómica de Adenovirus 7 asociado a infecciones severas del tracto respiratorio inferior. Medicina (Buenos Aires) 1993, 53:193-196

23. Mistchenko AS, Robaldo JF, Rosman FC, Koch ER, Kajon AE: Fatal adenovirus infection associated with new genome type. J Med Virol 1998, 54:233-236

24. Print $P$, Akerblon $P$, Adrian $T$ : Characterization of Adenovirus Subgenus D fiber genes. Virology 1995, 206:564-57I

25. Kajon A, Wadell G: Sequence analysis of $E 3$ region and fiber gene of human adenovirus genome type $7 \mathrm{~h}$. Virology 1996 , 215:190-196

26. Wadell G, Varsanyi TM, Lord A, Sutton RN: Epidemic outbreaks of adenovirus 7 with special reference to the pathogenicity of adenovirus genome type $\mathbf{7 b}$. American Journal of Epidemiology 1980, II 2:619-628

27. Hashido M, Mukouyama A, Sakae K, Tsuzuki H, Yamashita T, Inada T, Inouye S: Molecular and serological characterization of adenovirus genome type $7 \mathrm{~h}$ isolated in Japan. Epidemiol Infect 1999 , I 22(2):28I-286

\section{Pre-publication history}

The pre-publication history for this paper can be accessed here:

http://www.biomedcentral.com/1471-2431/2/6/prepub 